\title{
Effect of Podophyllotoxin Conjugated Stearic Acid Grafted Chitosan Oligosaccharide Micelle on Human Glioma Cells
}

\author{
Geng Huan Wang, ${ }^{1}$ He Ping Shen, Xuan Huang, ${ }^{2}$ Xiao Hong Jiang, ${ }^{2}$ Cheng Sheng Jin, Zheng Min Chu \\ Department of Neurosurgery, The Second Affiliated Hospital of Jiaxing University, Jiaxing, China \\ Department of Pharmacy, ${ }^{2}$ Medical College, Jiaxing University, Jiaxing, China
}

Objective : To study the physiochemical characteristics of podophyllotoxin (PPT) conjugated stearic acid grafted chitosan oligosaccharide micelle (PPT-CSO-SA), and evaluate the ability of the potential antineoplastic effects against glioma cells.

Methods : PPT-CSO-SA was prepared by a dialysis method. The quality of PPT-CSO-SA including micellar size, zeta potential, drug encapsulation efficiency and drug release profiles was evaluated. Glioma cells were cultured and treated with PPT and PPT-CSO-SA. The ability of glioma cells to uptake PPT-CSO-SA was observed. The proliferation of glioma cells was determined by 3-[4, 5-dimethyl2-thiazolyl]-2, 5-diphenyl-2H-tetrazolium bromide (MTT) assay. The apoptosis and morphology of U251 cells were observed by 4,6-Diamidino-2-phenylindole dihydrochloride (DAPI) dye staining. Cell cycle analysis was performed by flow cytometry. The migration ability of $\mathrm{U} 251$ cells was determined by wound healing test.

Results : PPT-CSO-SA had nano-level particle size and sustained release property. The encapsulation efficiency of drug reached a high level. The cellular uptake percentage of PPT in glioma cells was lower than that of PPT-CSO-SA $(p<0.05)$. The inhibitory effect of PPT-CSO-SA on glioma cells proliferation was significantly stronger than that of PPT $(p<0.05)$. The morphologic change of apoptosis cell such as shrinkage, karyorrhexis and karyopyknosis were observed. The percentage of U251 cells in G2/M phase increased significantly in the PPT-CSO-SA group compared with PPT group $(p<0.05)$. Compared with the PPT group, the cell migration ability of the PPT-CSO-SA group was significantly inhibited after 12 and 24 hours $(p<0.05)$.

Conclusion : PPT-CSO-SA can effectively enhance the glioma cellular uptake of drugs, inhibit glioma cells proliferation and migration, induce G2/M phase arrest of them, and promote their apoptosis. It may be a promising anti-glioma nano-drug.

Key Words : Podophyllotoxin · Nanoparticles · Glioma · Antineoplastic agents.

\section{INTRODUCTION}

The most common primary central nervous system tumours of adults are malignant gliomas ${ }^{13}$. Surgery combined with radiation and chemotherapy can improve survival rate and quality of life for patients, which is the standard treatment for malignant glioma ${ }^{13,23,27)}$. Despite the development of these treatments, most malignant gliomas are incurable tumours, and are resistant to chemotherapeutic agents ${ }^{4,13,26)}$. The average survival for patients with malignant gliomas was about

\footnotetext{
- Received : October 17, 2019 •Revised : December 15, 2019 •Accepted : December 27, 2019

- Address for reprints : He Ping Shen

Department of Neurosurgery, The Second Affiliated Hospital of Jiaxing University, North part of the ring road 1518, Jiaxing 314000, China

Tel : +86-82057903, Fax : +86-82314551, E-mail : shenege1977@126.com, ORCID : https://orcid.org/0000-0002-0418-5095
}

This is an Open Access article distributed under the terms of the Creative Commons Attribution Non-Commercial License (http://creativecommons.org/licenses/by-nc/4.0) which permits unrestricted non-commercial use, distribution, and reproduction in any medium, provided the original work is properly cited. 
14 months from first diagnosis ${ }^{4}$.

The natural podophyllotoxin (PPT) is mainly known for antiviral and antitumor properties ${ }^{1,8)}$. Its antitumor property has been attributed to inhibit microtubule polymerization and depolymerization activities, which leads to mitosis failure and cell cycle arrest ${ }^{3,21,22)}$. PPT is used as anticancer drug for lymphoma, leukemia, lung and testicular cancers, and it is also effective in treating neuroblastomas ${ }^{6}$. But its side effects including suppression of bone marrow, increased risk of secondary acute myelogenous leukemia and toxicity towards normal cells restrict their clinical application ${ }^{5,14,16,19)}$. It is important for antitumor treatment to develop novel agents with better cytotoxic selectivity and fewer side effects. In the past decade, the new drug delivery systems for PPT including solid lipid nanoparticles have been developed to improve drug stability, water solubility and reduce drug side effects ${ }^{20,24,28)}$. In recent years, chitosan oligosaccharide (CSO) can be regarded as a highly biocompatible, biodegradable, low immunogenicity, nontoxic material to build advanced drug delivery system ${ }^{2,9)}$. Stearic acid (SA) grafted CSO (CSO-SA) was prepared by coupling reaction through carboxyl group of SA and the amino groups of CSO, Which can form nanoparticle with positive electrical charge in aqueous solution and enter the cancer cells $^{10,11,25)}$. So it has been used as a good drug delivery system for loading antineoplastic drug to improve the antineoplastic activity $^{10,11,25)}$. To reduce the side effects and improve the anticancer activity of PPT, we have developed PPT conjugated SA grafted CSO micelles (PPT-CSO-SA). Basing the physiochemical characteristics properties of PPT-CSO-SA, micellar size, zeta potential, entrapment efficiency, in vitro drug release profiles, in vitro anticancer activities against human glioma cells were studied in detail.

\section{MATERIALS AND METHODS}

\section{Materials}

The study was approved by the Institutional Review Board (IRB No. jiaxingeryuan20170720). PPT was purchased from the Mansite Pharmaceutical Co. Ltd. (Chengdu, China). Chitosan ( $\mathrm{Mw}=450.0 \mathrm{~K}, 95 \%$ deacetylated degree) was supplied by Yuhuan Marine Biochemistry Co. Ltd. (Zhejiang, China). SA, 1-Ethyl-3-(3-dimethylaminopropyl) carbodiimide (EDC), 2,4,6-trinitrobenzene sulphonic acid (TNBS), and 3-[4, 5-di- methyl-2-thiazolyl]-2, 5-diphenyl-2H-tetrazolium bromide (MTT) reagent were supplied from Sigma (St. Louis, MO, USA). U87 cell, U251 cell, and fetal bovine serum (FBS) were supplied by the lisu-biotech Co, Ltd. (Shanghai, China).

\section{Preparation of CSO}

The 3\% chitosan was obtained by putting $30 \mathrm{~g}$ chitosan into $1000 \mathrm{~mL}$ deionized water (DI water). Then $12.5 \mathrm{~mL} 36.5 \%$ (w/v) hydrochloric acid was added, the temperature was raised to $50^{\circ} \mathrm{C}$, and chitosanase was added. The reactant was filtered through $0.45 \mu \mathrm{m}$ Millipore filter, and the CSO was prepared by lyophilization.

\section{Synthesis of CSO-SA}

As reported previously ${ }^{12}$, CSO-SA was synthesized by the EDC-mediated coupling reaction between amine groups of CSO and carboxyl group of SA. Briefly, CSO (0.15 g) was dissolved in $30 \mathrm{~mL}$ of DI water. Then SA (12 mg) in $15 \mathrm{~mL}$ ethanol was added. Finally, EDC (15 mg) was put in the compounds. The reaction solution was dialyzed by $20 \mathrm{~mL}$ ethanol for 24 hours, then throuth $20 \mathrm{~mL}$ distilled water using a dialysis membrane. The compounds were lyophilized, and CSOSA was prepared. The degree of amino-substitution for CSOSA was determined by TNBS method. Two millilitres of $0.1 \%$ aqueous TNBS solution and $2.0 \mathrm{~mL} 4 \% \mathrm{NaHCO}_{3}$ were put into $2.0 \mathrm{~mL}$ CSO-SA with different concentrations. The mixture was analysed at $344 \mathrm{~nm}$ by a ultraviolet spectrophotometer.

\section{Preparation of PPT-CSO-SA}

In the first place, CSO-SA (10.0 mg) was added to DI water (3.0 mL). Then PPT with different feeding ratio was added. The acquired compounds were probe-type ultrasonicated 30 times in ice bath. The resulting product was dialysed using a dialysis membrane for 24 hours in order to remove ethanol, and then lyophilized. Finally, a series of PPT-CSO-SA solutions with various PPT concentration were prepared.

\section{Characterization of CSO-SA and PPT-CSO-SA}

The average particle size, zeta potential of the micelles with $1 \mathrm{mg} / \mathrm{mL}$ of CSO-SA (25\% the substitute degree of amino groups) were examined by dynamic light scattering in deionized water. 


\section{Drug loading and encapsulation efficiencies of PPT-CSO- SA}

Briefly, $0.1 \mathrm{~mL}$ PPT-CSO-SA was put into an ultrafiltration tube and centrifuged for 10 minutes. The concentration of PPT was examined by high-performance liquid chromatography (HPLC) method. The drug loading amount and the drug entrapment efficiency were calculated from Equations 1) and 2), respectively. 1) Drug loading = (the total feeding amount of PPT - the amount of PPT in filtrate) / the total amount of micelles $\times 100 \%$. 2) Encapsulation efficiency $=$ (the total feeding amount of PPT - the amount of PPT in filtrate) / the total amount of PPT $\times 100 \%$.

\section{In vitro drug release rate from the PPT-CSO-SA}

PPT-CSO-SA was put into a dialysis bag, and the bag was added to a tube which contained phosphate buffer saline (PBS). The test was performed in shaking incubator, which was shaken at $100 \mathrm{rpm}$ at $37^{\circ} \mathrm{C}$. The amount of released drug was measured by HPLC with an emission wavelength of 292 $\mathrm{nm}$. The drug release test was performed in triplicate.

\section{Cell culture}

U251 cell and U87 cell were maintained in dulbecco's modified eagle medium (DMEM) added with 10\% FBS, $100 \mathrm{U} / \mathrm{mL}$ streptomycin and $100 \mathrm{U} / \mathrm{mL}$ penicillin at $37^{\circ} \mathrm{C}, 5 \% \mathrm{CO}_{2}$. The cells were subcultured by trypsin/EDTA.

\section{Cellular uptake of PPT}

U251 cell and U87 cell were seeded in the 24-well plate respectively. PPT and PPT-CSO-SA with 10\% PPT were put in, then the cells were continually incubated for $2,4,6,8,12$, and 24 hours. The cells were washed three times with PBS (pH 7.4) and ready for cellular uptake trial. The cellular uptake was observed by HPLC.

\section{MTT assay}

U87 cell and U251 cells were exposed to various concentrations of free PPT, PPT-CSO-SA and CSO-SA micelles at $37^{\circ} \mathrm{C}$ for 24,48 , and 72 hours. The cytotoxicity was evaluated by MTT. About $20 \mu \mathrm{L}$ of MTT was added and incubated for another 4 hours at $37^{\circ} \mathrm{C}$ at $5 \% \mathrm{CO}_{2}$. Each well was washed to discard medium and then $150 \mu \mathrm{L}$ of dimethyl sulfoxide (DMSO) was added. The absorbance of formazan product in each well was measured at $570 \mathrm{~nm}$ in a microplate reader. All the tests were performed in triplicate.

\section{Observation of apoptosis of U251 cell}

U251 cell was plated in $35 \mathrm{~mL}$ culture dish with $3.8 \times 10^{4}$ cells/well, and incubated for 24 hours. Cells were then incubated with $20 \mu \mathrm{g} / \mathrm{mL}$ PPT-CSO-SA, $50 \mu \mathrm{g} / \mathrm{mL}$ PPT-CSO-SA, $50 \mathrm{ug} / \mathrm{mL}$ PPT and $0.1 \%$ DMSO fetal calf serum DMEM for 24 hours at $37^{\circ} \mathrm{C}$. Cells were washed three times with PBS. Apoptosis induction effect was done by using 4,6-Diamidino2-phenylindole dihydrochloride (DAPI) staining method.

\section{Cell cycle analysis}

U251 cells treated with different drug $(20 \mu \mathrm{g} / \mathrm{mL}$ PPT and PPT-CSO-SA) for 24 hours were trypsinized and collected. Cells were washed with PBS for three times, placed in $70 \%$ ethanol, fixed at $4^{\circ} \mathrm{C}$, and added with RNase $\mathrm{A}$ and propidium iodide. Cell cycle analysis was performed by flow cytometry.

\section{Wound healing assay}

Took cells and inculated them for 24 hours in a 24-well plate, then scratched the cells with a sterile pipette to form longitudinal scratches. PBS was used to wash the plate three times. After adding the drug $(20 \mu \mathrm{g} / \mathrm{mL}$ PPT and PPT-CSOSA), cells were incubated for 24 hours. scratched area were photographed 0, 12, and 24 hours after wounding. Five fields

Table 1. The physicochemical characteristics of micelles

\begin{tabular}{lcccc}
\hline Micells & Size by number $(\mathbf{n m})$ & Size by Zave $(\mathbf{n m})$ & PI & Zeta potential $(\mathbf{m V})$ \\
\hline CSO-SA & $40.1 \pm 1.3$ & $406.2 \pm 1.2$ & 0.428 & $47.3 \pm 0.7$ \\
5\% PPT-CSO-SA & $30.8 \pm 0.7$ & $338.9 \pm 5.3$ & 0.421 & $39.9 \pm 0.9$ \\
10\% PPT-CSO-SA & $34.6 \pm 0.6$ & $358.7 \pm 2.1$ & 0.452 & $40.2 \pm 0.7$ \\
15\% PPT-CSO-SA & $35.9 \pm 0.9$ & $388.9 \pm 1.2$ & 0.489 & $42.1 \pm 0.8$ \\
\hline 20\% PPT-CSO-SA & $48.3 \pm 0.8$ & $389.7 \pm 3.4$ & 0.421 & $43.1 \pm 0.6$ \\
\hline
\end{tabular}

Values are presented as mean \pm standard deviation. We present the polydispersity index of the micelle size. PI : polydispersity index, CSO : chitosan oligosaccharide, SA : stearic acid, PPT : podophyllotoxin 
of view were taken for analysis in each group, and the experiment was repeated three times.

\section{Statistical analysis}

Quantitative data were expressed as mean \pm standard deviation of triplicate separate experiments, and statistical significance was tested by Student's t-test or analysis of variance. In all tests, $p<0.05$ was considered significant.

\section{RESULTS}

\section{Preparation of CSO-SA and PPT-CSO-SA}

The CSO-SA was prepared by coupling reaction between amine groups of CSO and carboxyl group of SA according to the previous reports. CSO-SA with different substitute degree of amino groups was prepared by regulating the amounts of EDC and SA. Polymer micelles were formed by the self-assembly of amphiphilic block copolymers in aqueous media with nanometer size. The physicochemical characteristics of micelles were showed on Table 1. Table 2 showed the drug loading content and entrapment efficiency of PPT-CSO-SA with varied PPT-loaded amounts. 10\% PPT-CSO-SA had highest drug entrapment efficiency which reached about $70 \%$.

\section{In vitro PPT release behaviors from PPT-CSO-SA}

PPT release from PPT-CSO-SA micelles with different drug contents was showed in the Fig. 1. PPT release from PPTCSO-SA was sustained.

\section{Cellular uptake assay}

Fig. 2 showed that cellular uptake percentages of PPT in glioma cells was lower than that of PPT-CSO-SA, and U87 cell uptake efficiency of PPT-CSO-SA was higher than U251 cell.

Table 2. Loading content and entrapment efficiency of micelles

\begin{tabular}{lcc}
\hline Loading amount of PPT (\%) & $\begin{array}{c}\text { Loading content } \\
(\%)\end{array}$ & $\begin{array}{c}\text { Entrapment } \\
\text { efficiency (\%) }\end{array}$ \\
\hline 5\% PPT-CSO-SA & $3.61 \pm 0.21$ & $48.32 \pm 2.15$ \\
\hline 10\% PPT-CSO-SA & $8.45 \pm 0.34$ & $69.31 \pm 3.18$ \\
\hline 15\% PPT-CSO-SA & $12.34 \pm 0.43$ & $65.42 \pm 1.56$ \\
\hline 20\% PPT-CSO-SA & $15.41 \pm 0.61$ & $57.15 \pm 1.38$ \\
\hline
\end{tabular}

Values are presented as mean \pm standard deviation. PPT : podophyllotoxin, CSO : chitosan oligosaccharide, SA : stearic acid
It was significant difference $(p<0.05)$.

\section{In vitro antitumor activities of micelles}

In vitro assay of micelles, we used CSO-SA (25\% the substitute degree of amino groups) as the carrier. In vitro cytotoxicity of PPT-CSO-SA was evaluated by MTT method. Table 3 showed the $50 \%$ inhibition concentration $\left(\mathrm{IC}_{50}\right)$ of the $\mathrm{CSO}$ SA, PPT, PPT-CSO-SA against U251 cell and U87 cell. Table 4 showed the cell inhibition rate of the different drug concentration. In contrast to PPT, PPT-CSO-SA had higher cytotoxicities against glioma cells $(p<0.05)$.

\section{Apoptosis inductive effect}

Apoptosis inductive effect of PPT-CSO-SA against glioma cells could be observed by DAPI dye staining. Fig 3 showed the morphologic change of apoptosis cell such as shrinkage, karyorrhexis and karyopyknosis by laser confocal microscope.

\section{Effects of PPT-CSO-SA on cell cycle distribution in $\mathrm{U} 251$ cells}

Table 5 showed that the percentage of U251 cells in G2/M phase increased significantly in the PPT-CSO-SA group compared with the control group and the PPT group $(p<0.05)$. It indicated that PPT-CSO-SA could induce G2/M phase arrest of glioma cells.

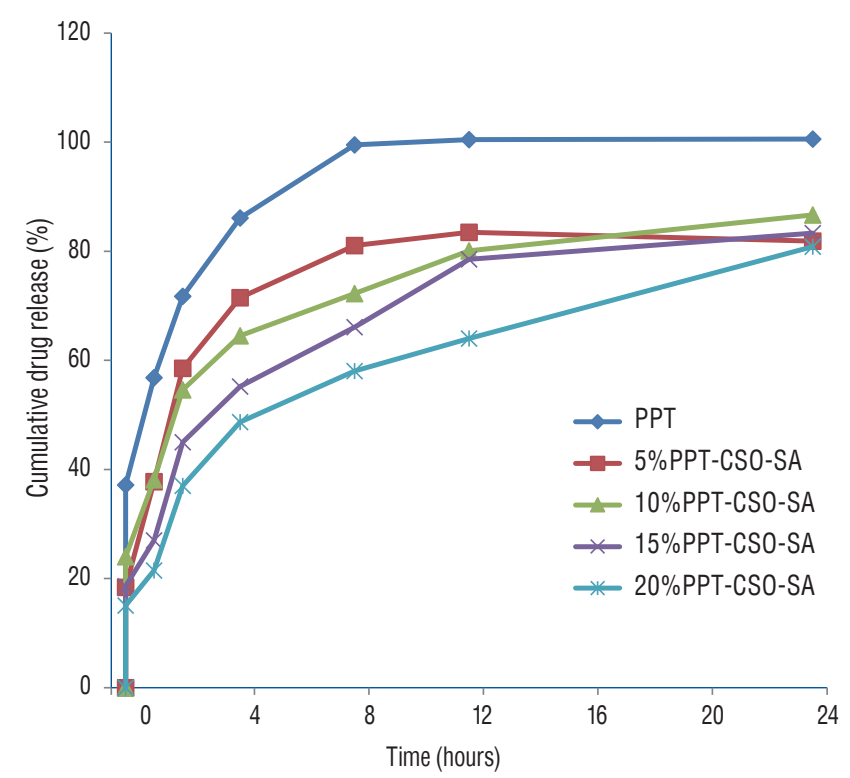

Fig. 1. Drug release profiles from 5\%, 10\%, 15\%, and 20\% PPT-CSO-SA in PBS ( $\mathrm{pH}$ 7.4) solution. PPT : podophyllotoxin, CSO : chitosan oligosaccharide, $\mathrm{SA}$ : stearic acid. 
Wound healing assay to detect cell migration ability

As showed in Table 6 and Fig. 4, compared with the PPT group, the cell migration ability of the PPT-CSO-SA group was significantly inhibited after 12 and 24 hours $(p<0.05)$.

\section{DISSCUSION}

Malignant gliomas are the most aggressive brain tumors ${ }^{17}$. PPT is effective in treating neuroblastomas ${ }^{6}$. But its side effect

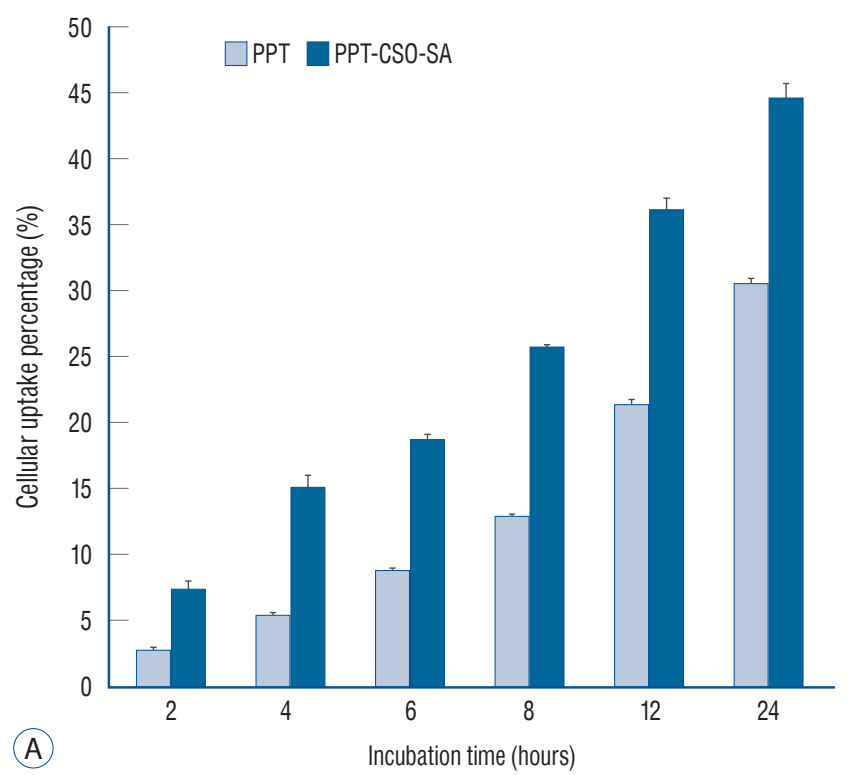

(A)

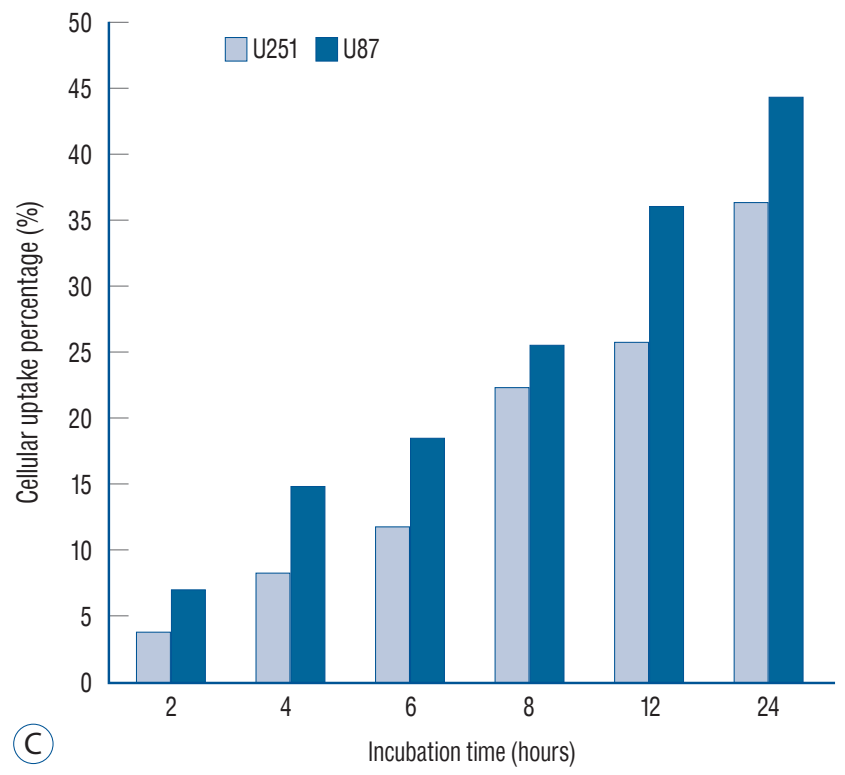

limits the clinical application. In oder to reduce PPT side effects and improve its efficiency of antitumor activities, we develop the PPT-CSO-SA.

The nanoparticle size is very significant for the drug delivery system due to the enhanced permeability and retention effect ${ }^{15)}$. Owing to this effect, the micelles can target and be largely accumulated to tumor tissue, which can reduce side effects and improve drug effciency ${ }^{12}$. CSO-SA has very small size, hydrophilic surface. These characteristics contributed to a prolonged circulation and could evade the mononuclear phagocyte system ${ }^{7,12,18)}$. Its molecular target of drug was pres-

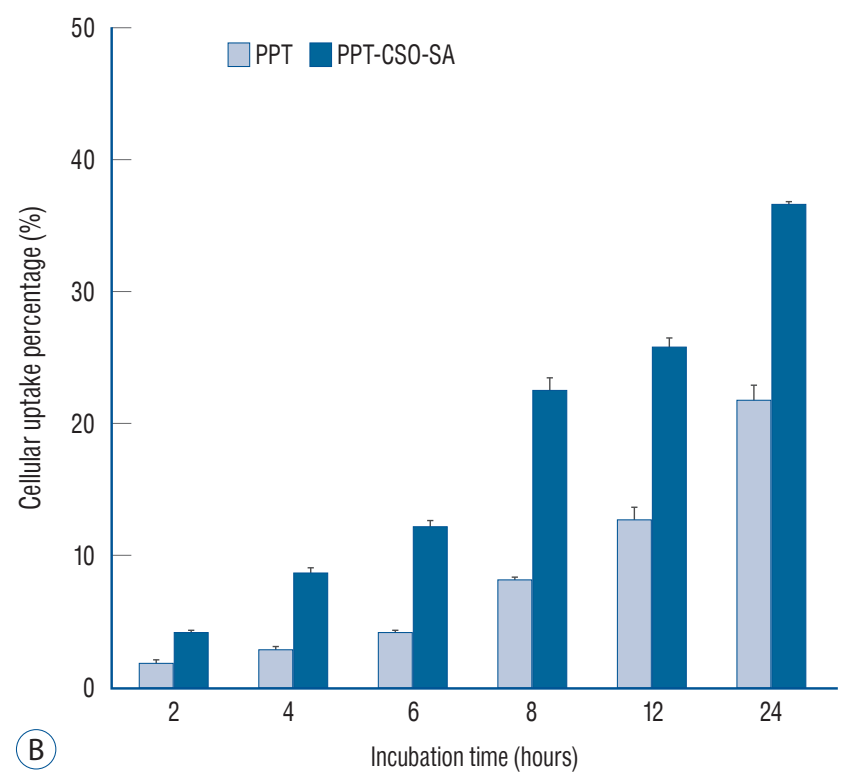

Fig. 2. Cellular uptake percentages of PPT and PPT-CSO-SA in different glioma cells against incubation time : (A) U251, (B) U87. Cellular uptake percentage of PPT in PPT-CSO-SA by U251, U87 cells within different incubation time (C). PPT : podophyllotoxin, CSO : chitosan oligosaccharide, $\mathrm{SA}$ : stearic acid. 
ent in the tumour cells ${ }^{12)}$. CSO-SA could self-assemble to form nanoscale micelles in aqueous solution ${ }^{9,11}$. Because of highly hydrophobic nature of PPT, after the PPT was loaded the CSO-SA, the majority of drugs were located in the cores of micelles. The micelles could greatly improve the water solubility of insoluble drugs.

The particle size of PPT-CSO-SA was in the range of 30.8$48.3 \mathrm{~nm}$. The decrease of micelle size after loading is mainly due to the increase of hydrophobicity of CSO-SA. When PPTloaded increased, the particle size increased a little. Zave size of PPT-CSO-SA had similar trends which ranged from 338.9 $\mathrm{nm}$ to $389.7 \mathrm{~nm}$. Zeta potentials of micelles decreased in comparison with CSO-SA when PPT was loaded to CSO-SA. With the increase of the PPT-loaded, the particle size gradually increases, and the surface charge also gradually increases with the increase of the dose. The reason is that drug loaded could decrease the surface charge density.

Table 3. IC $\mathrm{I}_{50}$ values of CSO-SA, PPT and PPT-CSO-SA against U251 cells and $\mathrm{U} 87$ cells

\begin{tabular}{lccr}
\hline \multirow{2}{*}{ Sample } & \multicolumn{3}{c}{$\mathrm{IC}_{50}(\boldsymbol{\mu g} / \mathrm{mL})$} \\
\cline { 2 - 4 } & $\mathbf{2 4}$ hours & \multicolumn{1}{c}{$\mathbf{4 8}$ hours } & $\mathbf{7 2}$ hours \\
\hline U251 cells & & & \\
CSO-SA & $199.62 \pm 11.48$ & $198.96 \pm 6.40$ & $112.04 \pm 7.11$ \\
PPT & $9.10 \pm 0.12$ & $8.21 \pm 0.20$ & $5.59 \pm 0.10$ \\
PPT-CSO-SA & $7.18 \pm 0.82$ & $5.71 \pm 0.18$ & $2.57 \pm 0.12$ \\
U87 cells & & & \\
CSO-SA & $195.12 \pm 10.15$ & $181.93 \pm 5.45$ & $110.04 \pm 6.12$ \\
PPT & $8.80 \pm 0.14$ & $7.86 \pm 0.21$ & $5.09 \pm 0.15$ \\
PPT-CSO-SA & $6.17 \pm 0.52$ & $4.70 \pm 0.16$ & $2.07 \pm 0.13$ \\
\hline
\end{tabular}

Values are presented as mean \pm standard deviation. CSO : chitosan oligosaccharide, SA : stearic acid, PPT : podophyllotoxin
Release of the drug from micelles is important for the drug delivery system. In this study, PPT is highly hydrophobic and forms attraction with the inner core of the micelles. The free PPT was released mostly within 4 hours, however, the release of PPT-CSO-SA ranged from $48.69 \%$ to $71.50 \%$ at the same time. Therefore PPT release from micelles was sustained. Fig. 1 showed that the more PPT content was, the slower the release

Table 4. Cell inhibition rate of PPT and PPT-CSO-SA against U251 cells and $\mathrm{U} 87$ cells

\begin{tabular}{lccc}
\hline \multirow{2}{*}{ Group } & \multicolumn{3}{c}{ Inhibition rate (\%) } \\
\cline { 2 - 4 } U251 cells & 24 hours & 48 hours & $\mathbf{7 2 ~ h o u r s}$ \\
PPT-CSO-SA & & & \\
$5 \mu \mathrm{g} / \mathrm{mL}$ & $48.68 \pm 3.29$ & $58.25 \pm 2.15$ & $83.32 \pm 3.13$ \\
$10 \mu \mathrm{g} / \mathrm{mL}$ & $60.24 \pm 2.64$ & $70.24 \pm 3.12$ & $91.43 \pm 2.34$ \\
$20 \mu \mathrm{g} / \mathrm{mL}$ & $79.23 \pm 2.56$ & $90.12 \pm 3.56$ & $95.23 \pm 2.53$ \\
PPT & & & \\
$5 \mu \mathrm{g} / \mathrm{mL}$ & $39.51 \pm 4.86$ & $41.16 \pm 3.82$ & $65.17 \pm 2.35$ \\
$10 \mu \mathrm{g} / \mathrm{mL}$ & $48.22 \pm 3.82$ & $53.04 \pm 4.64$ & $69.31 \pm 3.16$ \\
$20 \mu \mathrm{g} / \mathrm{mL}$ & $59.04 \pm 2.52$ & $74.92 \pm 8.27$ & $86.29 \pm 1.32$ \\
U87 cells & & & \\
PPT-CSO-SA & & & $85.33 \pm 3.21$ \\
$5 \mu \mathrm{g} / \mathrm{mL}$ & $53.69 \pm 3.31$ & $65.20 \pm 2.05$ & $93.41 \pm 2.43$ \\
$10 \mu \mathrm{g} / \mathrm{mL}$ & $65.14 \pm 2.54$ & $74.21 \pm 3.21$ & $98.13 \pm 2.34$ \\
$20 \mu \mathrm{g} / \mathrm{mL}$ & $82.21 \pm 2.45$ & $92.10 \pm 3.18$ & \\
PPT & & & $71.34 \pm 3.18$ \\
$5 \mu \mathrm{g} / \mathrm{mL}$ & $40.52 \pm 4.45$ & $48.15 \pm 3.35$ & $67.19 \pm 2.14$ \\
$10 \mu \mathrm{g} / \mathrm{mL}$ & $50.12 \pm 3.95$ & $55.08 \pm 4.59$ & \\
$20 \mu \mathrm{g} / \mathrm{mL}$ & $62.14 \pm 2.33$ & $78.90 \pm 6.29$ & \\
\hline
\end{tabular}

Values are presented as mean \pm standard deviation. PPT : podophyllotoxin, CSO : chitosan oligosaccharide, SA : stearic acid
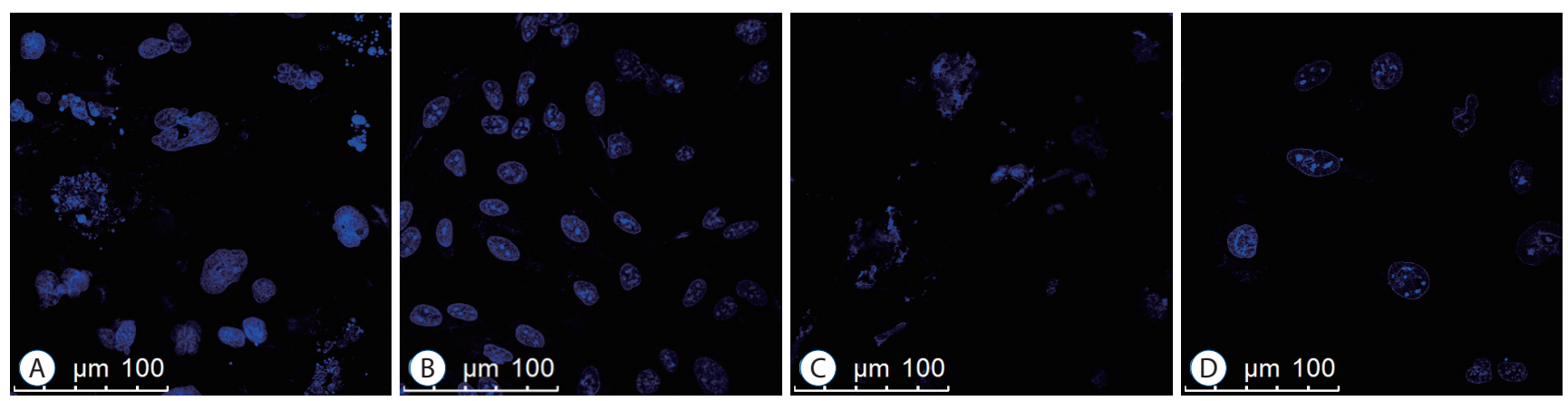

Fig. 3. Apoptosis of U251 cells induced by PPT-CSO-SA (A : DMSO was used as control; B and C : $20 \mathrm{ug} / \mathrm{mL}$ and $50 \mathrm{ug} / \mathrm{mL}$ PPT-CSO-SA; D : $50 \mathrm{ug} / \mathrm{mL}$ PPT). PPT : podophyllotoxin, CSO : chitosan oligosaccharide, SA : stearic acid. 
speed was. The slowest release was 20\% PPT-CSO-SA, the fastest release was 5\% PPT-CSO-SA. The slower release of the PPT-CSO-SA was chiefly due to the hydrophobic interaction between CSO-SA and PPT. In addition, micelle release is related to particle size. Because the particle size is an important factor to influence its surface area. The larger its contacting

Table 5. The effects of PPT and PPT-CSO-SA on cell cycle of U251 cells

\begin{tabular}{lccr}
\hline Group & G0/G1 & S & G2/M \\
\hline Control & $52.35 \pm 5.45$ & $34.05 \pm 2.56$ & $13.6 \pm 1.02$ \\
PPT & $50.21 \pm 4.64$ & $30.34 \pm 2.09$ & $19.45 \pm 1.84$ \\
\hline PPT-CSO-SA & $47.62 \pm 4.35$ & $27.79 \pm 2.54$ & $24.59 \pm 2.01$ \\
\hline
\end{tabular}

Values are presented as mean \pm standard deviation. PPT : podophyllotoxin, CSO : chitosan oligosaccharide, SA : stearic acid area with the medium is, the faster its drug release of the micelles is ${ }^{9}$. With the increasing of drug loaded, the size of micelles rose, the surface area decreased, and release of the drug slowed.

Fig. 2 showed cellular uptake of PPT-CSO-SA was above that of PPT against different glioma cells in different incuba-

Table 6. Wound healing rate of PPT and PPT-CSO-SA against U251 cells

\begin{tabular}{lcc}
\hline \multirow{2}{*}{ Group } & \multicolumn{2}{c}{ Wound healing rate (\%) } \\
\cline { 2 - 3 } & $\mathbf{1 2}$ hours & $\mathbf{2 4}$ hours \\
\hline CSO-SA & $52.40 \pm 4.96$ & $63.39 \pm 7.82$ \\
PPT & $32.24 \pm 3.85$ & $47.63 \pm 5.09$ \\
PPT-CSO-SA & $11.89 \pm 1.67$ & $21.20 \pm 1.42$ \\
\hline
\end{tabular}

Values are presented as mean \pm standard deviation. PPT : podophyllotoxin, CSO : chitosan oligosaccharide, SA : stearic acid
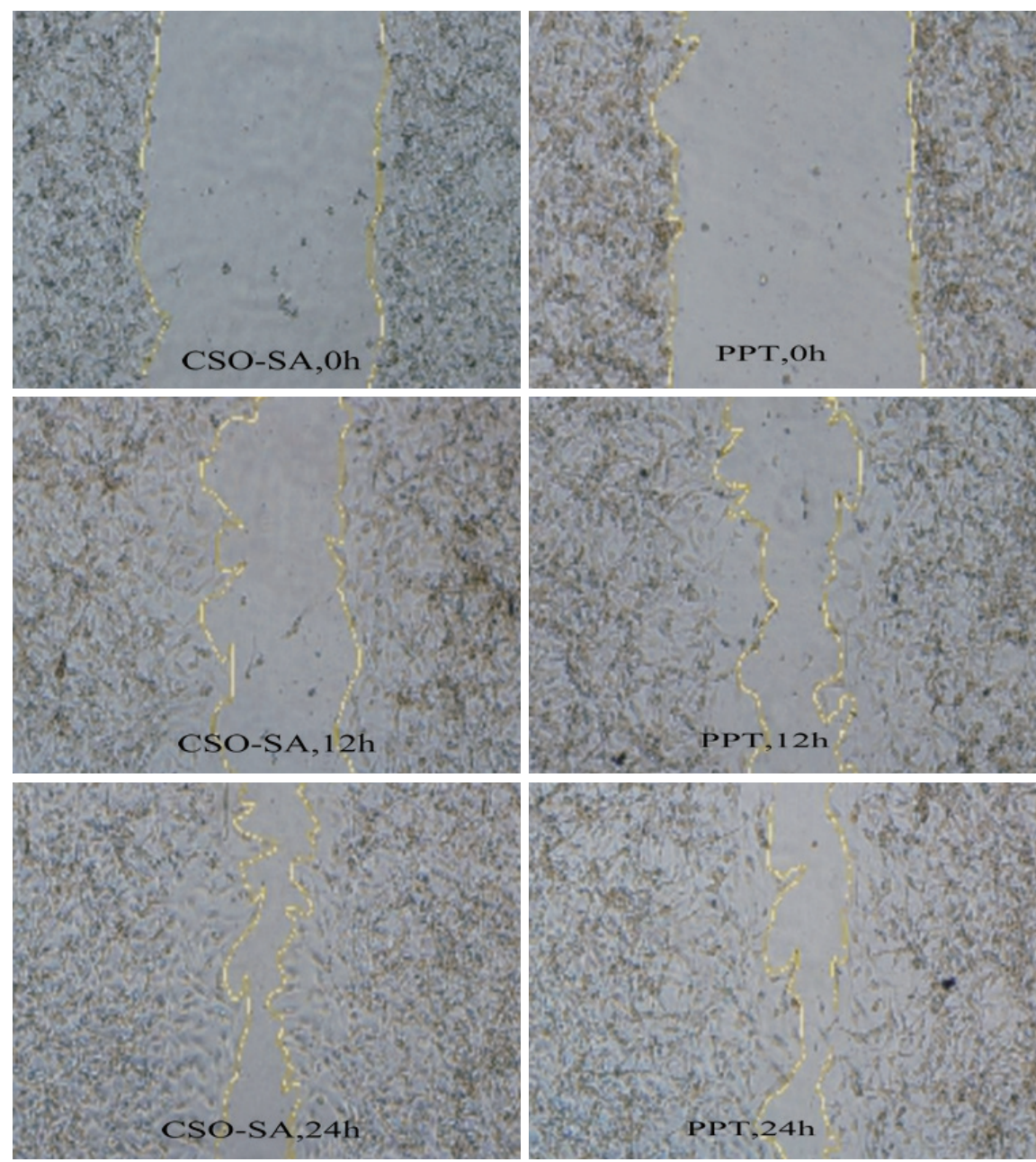
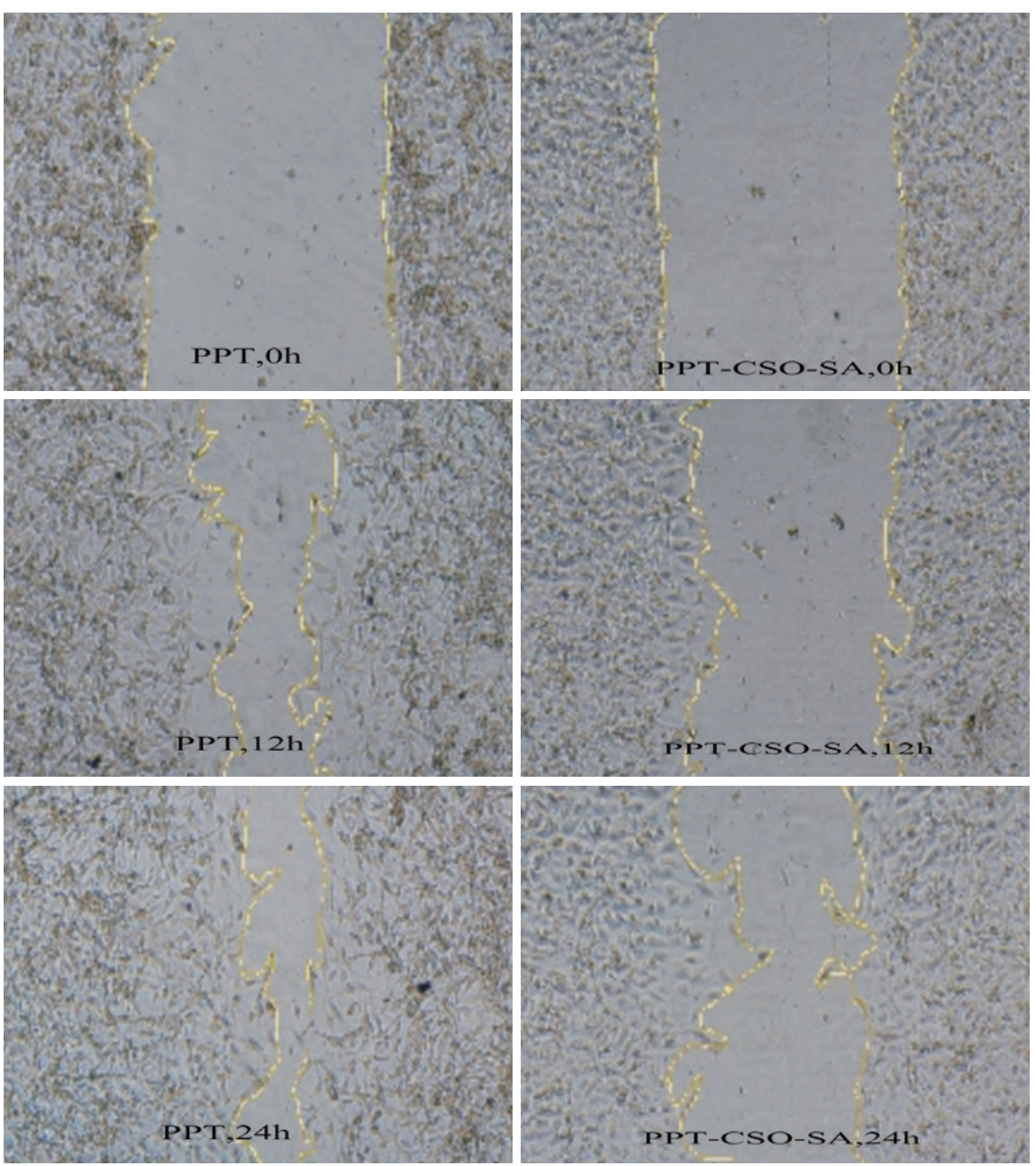

Fig. 4. Compared with the PPT group, the cell migration ability of the PPT-CSO-SA group was significantly inhibited after 12 and 24 hours. PPT: podophyllotoxin, CSO : chitosan oligosaccharide, SA : stearic acid. 
tion time. In vitro assay, we found that PPT-CSO-SA was higher cytotoxicities against glioma cells compared with PPT. It was probably due to the increased cellular uptake quantity of PPT in glioma cells. The result meant that PPT-CSO-SA had greater ability of internalization and could deliver more PPT into glioma cells. With the increasing of PPT-CSO-SA, the glioma cell inhibition rate increased. It was in accord with the cytotoxicity. Tables 5 and 6, Figs. 3 and 4 showed PPTCSO-SA could induce G2/M phase arrest of glioma cells, inhibit U251 cell migration and promote their apoptosis, which was one of the reasons why PPT-CSO-SA could treat gliomas.

\section{CONCLUSION}

We successfully prepared PPT-CSO-SA in this study. The polymeric micelles were in the range of $30.8-48.3 \mathrm{~nm}$ and had the sustained release behavior. The drug entrapment efficiency reached up to $69.31 \%$. The PPT-CSO-SA was more effective to suppress glioma cells than free PPT. The reason was that PPT-CSO-SA could enhance the glioma cellular uptake of drugs, inhibit glioma cells proliferation and migration, induce $\mathrm{G} 2 / \mathrm{M}$ phase arrest of them, and promote their apoptosis. In a word, the PPT-CSO-SA could be considered as one of the promising anti-glioma nano-drugs.

\section{CONFLICTS OF INTEREST}

No potential conflict of interest relevant to this article was reported.

\section{INFORMED CONSENT}

This type of study does not require informed consent

\section{AUTHOR CONTRIBUTIONS}

\author{
Conceptualization : GHW, HPS, CSJ \\ Data curation : XH, XHJ \\ Formal analysis : ZMC \\ Funding acquisition : GHW
}

\author{
Methodology : HPS, XH \\ Project administration : GHW \\ Writing - original draft : GHW \\ Writing - review \& editing : HPS
}

\section{ORCID}

Geng Huan Wang https://orcid.org/0000-0002-8967-7952

He Ping Shen https://orcid.org/0000-0002-0418-5095

Xuan Huang https://orcid.org/0000-0002-1656-1000

Xiao Hong Jiang https://orcid.org/0000-0001-6584-8043

Cheng Sheng Jin https://orcid.org/0000-0003-0807-5536

Zheng Min Chu https://orcid.org/0000-0002-3861-8725

\section{- Acknowledgements}

This study was supported by Social Development Project of Zhejiang Public Welfare Technology Research (LGF19H160013) and Zhejiang provincial medical science and technology program (2013KYA199).

\section{References}

1. Castro A, del Corral JM, Gordaliza M, Grande C, Gómez-Zurita A, García-Grávalos D, et al. : Synthesis and cytotoxicity of podophyllotoxin analogues modified in the A ring. Eur J Med Chem 38 : 65-74, 2003

2. De Campos AM, Sánchez A, Alonso MJ : Chitosan nanoparticles: a new vehicle for the improvement of the delivery of drugs to the ocular surface. Application to cyclosporin A. Int J Pharm 224 : 159-168, 2001

3. Desbène $S$, Giorgi-Renault $S$ : Drugs that inhibit tubulin polymerization: the particular case of podophyllotoxin and analogues. Curr Med Chem Anticancer Agents 2 : 71-90, 2002

4. Ellingson BM, Cloughesy TF, Zaw T, Lai A, Nghiemphu PL, Harris R, et al. : Functional diffusion maps (fDMs) evaluated before and after radiochemotherapy predict progression-free and overall survival in newly diagnosed glioblastoma. Neuro Oncol 14 : 333-343, 2012

5. Felix CA : Secondary leukemias induced by topoisomerase-targeted drugs. Biochim Biophys Acta 1400 : 233-255, 1998

6. Fisher RI, Gaynor ER, Dahlberg S, Oken MM, Grogan TM, Mize EM, et al. : A phase III comparison of CHOP vs. m-BACOD vs. ProMACE-CytaBOM vs. MACOP-B in patients with intermediate- or high-grade non-Hodgkin's lymphoma: results of SWOG-8516 (Intergroup 0067), the National High-Priority Lymphoma Study. Ann Oncol 5 Suppl 2 : 91-95, 1994

7. Gaucher G, Dufresne MH, Sant VP, Kang N, Maysinger D, Leroux JC : Block copolymer micelles: preparation, characterization and application 
in drug delivery. J Control Release 109 : 169-188, 2005

8. Gordaliza M, García PA, del Corral JM, Castro MA, Gómez-Zurita MA : Podophyllotoxin: distribution, sources, applications and new cytotoxic derivatives. Toxicon 44 : 441-459, 2004

9. Hu FQ, Liu LN, Du YZ, Yuan H : Synthesis and antitumor activity of doxorubicin conjugated stearic acid-g-chitosan oligosaccharide polymeric micelles. Biomaterials 30 : 6955-6963, 2009

10. Hu FQ, Ren GF, Yuan H, Du YZ, Zeng $S$ : Shell cross-linked stearic acid grafted chitosan oligosaccharide self-aggregated micelles for controlled release of paclitaxel. Colloids Surf B Biointerfaces 50 : 97-103, 2006

11. Hu FQ, Zhao MD, Yuan H, You J, Du YZ, Zeng S : A novel chitosan oligosaccharide-stearic acid micelles for gene delivery: properties and in vitro transfection studies. Int J Pharm 315 : 158-166, 2006

12. Huang $X$, Huang $X$, Jiang $X H$, Hu FQ, Du $Y Z$, Zhu QF, et al. : In vitro antitumour activity of stearic acid-g-chitosan oligosaccharide polymeric micelles loading podophyllotoxin. J Microencapsul 29 : 1-8, 2012

13. Jansen M, Yip S, Louis DN : Molecular pathology in adult gliomas: diagnostic, prognostic, and predictive markers. Lancet Neurol 9 : 717-726, 2010

14. Lara PN, Natale R, Crowley J, Lenz HJ, Redman MW, Carleton JE, et al. : Phase III trial of irinotecan/cisplatin compared with etoposide/cisplatin in extensive-stage small-cell lung cancer: clinical and pharmacogenomic results from SWOG S0124. J Clin Oncol 27 : 2530-2535, 2009

15. Li SD, Huang $L$ : Pharmacokinetics and biodistribution of nanoparticles. Mol Pharm 5 : 496-504, 2008

16. López-Pérez JL, del Olmo E, de Pascual-Teresa B, Abad A, San Feliciano A : Synthesis and cytotoxicity of hydrophobic esters of podophyllotoxins. Bioorg Med Chem Lett 14 : 1283-1286, 2004

17. Louis DN, Ohgaki H, Wiestler OD, Cavenee WK, Burger PC, Jouvet $A$, et al. : The 2007 WHO classification of tumours of the central nervous system. Acta Neuropathol 114 : 97-109, 2007

18. Moreira JN, Gaspar R, Allen TM : Targeting Stealth liposomes in a murine model of human small cell lung cancer. Biochim Biophys Acta 1515 : 167-176, 2001
19. Pedersen-Bjergaard $\mathrm{J}$ : Radiotherapy- and chemotherapy-induced myelodysplasia and acute myeloid leukemia. A review. Leuk Res 16 : 61-65, 1992

20. Qin L, Xue M, Wang W, Zhu R, Wang S, Sun J, et al. : The in vitro and in vivo anti-tumor effect of layered double hydroxides nanoparticles as delivery for podophyllotoxin. Int J Pharm 388 : 223-230, 2010

21. Sackett DL : Podophyllotoxin, steganacin and combretastatin: natural products that bind at the colchicine site of tubulin. Pharmacol Ther 59 : 163-228, 1993

22. Schönbrunn E, Phlippen W, Trinczek B, Sack S, Eschenburg S, Mandelkow EM, et al. : Crystallization of a macromolecular ring assembly of tubulin liganded with the anti-mitotic drug podophyllotoxin. J Struct Biol 128 : 211-215, 1999

23. Stummer W, Meinel T, Ewelt C, Martus P, Jakobs O, Felsberg J, et al. : Prospective cohort study of radiotherapy with concomitant and adjuvant temozolomide chemotherapy for glioblastoma patients with no or minimal residual enhancing tumor load after surgery. J Neurooncol 108 : 89-97, 2012

24. Venishetty VK, Komuravelli R, Kuncha M, Sistla R, Diwan PV : Increased brain uptake of docetaxel and ketoconazole loaded folate-grafted solid lipid nanoparticles. Nanomedicine 9 : 111-121, 2013

25. You J, Hu FQ, Du YZ, Yuan H : Polymeric micelles with glycolipid-like structure and multiple hydrophobic domains for mediating molecular target delivery of paclitaxel. Biomacromolecules 8 : 2450-2456, 2007

26. Zhan C, Lu W : The blood-brain/tumor barriers: challenges and chances for malignant gliomas targeted drug delivery. Curr Pharm Biotechnol $13: 2380-2387,2012$

27. Zhang L, Wu X, Xu T, Luo C, Qian J, Lu Y : Chemotherapy plus radiotherapy versus radiotherapy alone in patients with anaplastic glioma: a systematic review and meta-analysis. J Cancer Res Clin Oncol 139 : 719-726, 2013

28. Zhu RR, Qin LL, Wang M, Wu SM, Wang SL, Zhang R, et al. : Preparation, characterization, and anti-tumor property of podophyllotoxinloaded solid lipid nanoparticles. Nanotechnology 20 : 055702, 2009 